\title{
Perancangan Sistem Pengukuran dan Monitoring Pemakaian Air Rumah PDAM Berbasis SMS (Short Message Service)
}

\author{
Masruchi $^{1}$, V. Vekky R. Repi ${ }^{1}$, Fitria Hidayanti ${ }^{1}$ \\ ${ }^{1}$ Program Studi Teknik Fisika, Fakultas Teknik dan Sains, Universitas Nasional, J1. Sawo \\ Manila, Pejaten, Pasar Minggu, Jakarta Selatan - Jakarta 12520 \\ Korespondensi: vekky_repi@yahoo.com
}

\begin{abstract}
ABSTRAK. Sumber daya mineral yang ada di indonesia ini sangat banyak sekali tak terkecuali untuk kebutuhan sehari-hari, air sangat di butuhkan oleh manusia buat mandi, minum dan mencuci. Dalam pemakaian air terkadang kita tidak memperhatikan jumlah air yang digunakan sehingga kita terlalu boros untuk memanfaatkannya. Dalam penelitian ini di bahas tentang bagaimana kita dapat memanfaatkan jumlah air dalam kehidupan seharihari sehingga tidak boros dalam pemakaiannya alat ini dapat memonitoring jumlah debit atau pemakaian air yang telah di gunakan sehingga kita tidak boros dalam memanfaatkannya. Dalam pemakaian air ini biasanya petugas PDAM (Perusahaan Daerah Air Minum) memonitoring dari rumah ke rumah untuk mencatat berapa debit air yang telah di gunakan oleh konsumen ( pelanggan ). Alat ini memudahkan konsumen supaya bisa mengetahui berapa rupiah atau debit air yang di gunakan dengan menggunakan sms (short message service) dan flowmeter sebagai sensor. Petugas tidak perlu datang ke rumah untuk mengecek atau mencatat berapa debit air yang telah di gunakan karena data tersebut sudah tercatat ke dalam server.
\end{abstract}

Kata kunci: Sistem Pengukuran, Distribusi Pemakaian Air, Aplikasi Sistem sms, Debit air, flowmeter.

\section{PENDAHULUAN}

Air sangat berguna dalam kehidupan sehari hari bagi manusia karena dapat digunakan buat minum, mencuci dan mandi. dalam pemakaian manusia tidak pernah memperhatikan berapa jumlah debit air yang telah digunakan, inilah yang menjadi persoalan buat manusia karena tidak bisa memotoring jumlah pemakaian air tersebut, sehingga boros dalam pemakaiannya dikarenakan tidak dapat mengontrol dalam pemakaiannya [1].

Dalam penelitian ini saya merancang alat untuk memonitoring jumlah pemakaian air supaya dapat dikontrol sehingga pemakaian air dapat dimonitoring oleh pelanggan atau konsumen. Konsumen dapat mengetahui jumlah pemakaiannya dalam sehari - hari dengan sms (short message service) ke server, server akan otomatis langsung mengirim sms ke pelanggan jumlah debit pemakaian air dalam rupiah. Sehingga memudahkan pelanggan untuk mengontrol pemakaian air tersebut jika kondisi pemakaian air sudah melebihi batas pemakaian.

Kemajuan ilmu pengetahuan dan teknologi, terutama di bidang elektronika dan instrumentasi, pada prinsipnya dapat diterapkan untuk mengatasi masalah tersebut, yaitu dengan membuat alat ukur dan monitoring pemakaian air yang bekerja secara elektronik. Volume air ini dapat diukur dengan menggunakan sensor laju aliran air flowmeter, yang kemudian diproses oleh mikrokontroler dan ditampilkan dalam bentuk digital, berupa volume dan biaya [2].

\section{LANDASAN TEORI}

Air merupakan kebutuhan pokok manusia dan mempunyai banyak kegunaan antara lain untuk minum, mandi, mencuci dan lain sebagainya. Di perkotaan, pelayanan jasa air bersih umumnya diselenggarakan oleh pemerintah melalui PDAM (Perusahaan Daerah Air Minum) [3].

PDAM merupakan perusahaan milik daerah yang bergerak di bidang pengolahan dan pendistribusian air bersih, beberapa fasilitas yang digunakan dalam pemproses air bersih antara 
lain : intake, menara air, clarifier, pulsator, filter dan reservoir. semua peralatan tadi dioperasikan melalui system computer selain berbagai macam alat PDAM juga menggunakan bahan kimia seperti : kaporit dan tawas dalam proses pengolahan air bersih air yang diproduksi dipantau kualitasnya oleh laboratorium sehingga dapat di hasilkan air bersih yang memenuhi standar kesehatan. PDAM mempunyai cara untuk mengetahui jumlah air bersih yang digunakan warga/penduduk dengan memasang meteran pada pipa air yang masuk ke rumah-rumah. Selanjutnya, setiap bulan akan ada petugas PDAM yang mendatangi rumah penduduk dan mencatat volume air yang digunakan di masing-masing rumah penduduk.

Water Flow sensor terdiri dari tubuh katup plastik, rotor air, dan sensor hall efek. Ketika air mengalir melalui, gulungan rotor-rotor. Kecepatan perubahan dengan tingkat yang berbeda aliran. Sesuai sensor hall efek output sinyal pulsa. Kelebihan sensor ini adalah hanya membutuhkan 1 sinyal (SIG) selain jalur 5V de dan Ground.Perhatikan gambar di bawah ini [4].
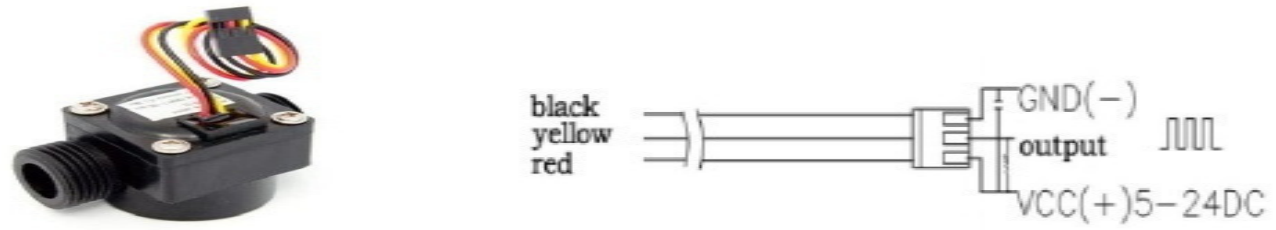

GAMBAR 1. Fisik dan skematik instalasi Water Flow Sensor G1/2 [2].

Real-time clock disingkat RTC adalah jam di komputer yang umumnya berupa sirkuit terpadu yang berfungsi sebagai pemelihara waktu. RTC umumnya memiliki catu daya terpisah dari catu daya komputer (umumnya berupa baterai litium) sehingga dapat tetap berfungsi ketika catu daya komputer terputus. Kebanyakan RTC menggunakan oskilator kristal.

AVR merupakan salah satu jenis mikrokontroler yang di dalamnya terdapat berbagai macam fungsi. Perbedaannya pada mikro yang pada umumnya digunakan seperti MCS51 adalah pada AVR tidak perlu menggunakan oscillator eksternal karena di dalamnya sudah terdapat internal oscillator. Selain itu kelebihan dari AVR adalah memiliki Power-On Reset, yaitu tidak perlu ada tombol reset dari luar karena cukup hanya dengan mematikan supply, maka secara otomatis AVR akan melakukan reset. Untuk beberapa jenis AVR terdapat beberapa fungsi khusus seperti ADC, EEPROM sekitar 128 byte sampai dengan 512 byte [5].

PDIP

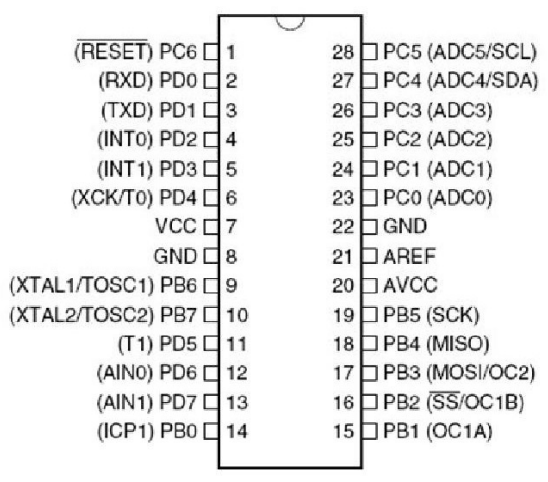

GAMBAR 2. Konfigurasi Pin Atmega8 [4].

ATmega8 memiliki 28 Pin, yang masing-masing pinnya memiliki fungsi yang berbeda-beda baik sebagai port maupun fungsi yang lainnya. Berikut akan dijelaskan fungsi dari masingmasing kaki ATmega8. Mikrokontroler AVR Atmega 8 memiliki Port USART pada Pin 2 dan Pin 3 untuk melakukan komunikasi data antara mikrokontroler dengan mikrokontroler ataupun mikrokontroler dengan komputer. USART dapat difungsikan sebagai transmisi data sinkron, dan asinkron. Sinkron berarti clock yang digunakan antara transmiter dan receiver satu sumber clock. Sedangkan asinkron berarti transmiter dab receiver mempunyai sumber clock sendiri- 
sendiri. USART terdiri dalm tiga blok yaitu clock generator, transmiter, dan receiver [6].

Salah satu media komunikasi yang cukup diminati ialah pesan singkat (SMS). Agar SMS tersebut dapat terhubung dengan database, maka perlu dibangun sebuah system yang disebut SMS Gateway. Istilah gateway dapat diartikan sebagai pintu gerbang bagi penyebaran informasi. Dalam dunia komputer gateway dapat diartikan sebagai jembatan penghubung antara satu sistem dengan sistem yang lain.

Dalam artian luas SMS Gateway adalah sebuah aplikasi yang merubah proses SMS dari MobileEquipment ke PC/Laptop, SMS Seperti layaknya fitur di telepon selular, tetapi ada perbedaan dari segi fitur, dan fungsi yang bisa dibuat berdasarkan kebutuhan bisnis. Dengan adanya software SMS Gateway dapat mengatur SMS lewat PC atau laptop dengan mudah dan cepat. Seperti mengatur kontak dengan menggunakan Excel atau notepad, mengatur SMS keluar, mengirim SMS per kelompok, mengirim SMS khusus pelanggan, membuat SMS dengan jawaban otomatis yang bisa diatur isi SMSnya [7].

BASCOM-AVR adalah program basic compiler berbasis windows untuk mikrokontroler keluarga AVR merupakan pemrograman dengan bahasa tingkat tinggi " BASIC " yang dikembangkan dan dikeluarkan oleh MCS elektronika sehingga dapat dengan mudah dimengerti atau diterjemahkan. Dalam program BASCOM-AVR terdapat beberapa kemudahan, untuk membuat program software ATmega 16, seperti program simulasi yang sangat berguna untuk melihat, simulasi hasil program yang telah kita buat, sebelum program tersebut kita download ke IC atau ke mikrokontroler [8].

\section{METODOLOGI PENELITIAN}

Perancangan dan pembuatan alat ini terdiri dari pompa airkemudian melewati meteran air yang terdapat sensor flowmeter yang mengirimkan data ke mikrokontroller untuk diolah, data tersebut kemudian ditampilkan ke personal computer (PC) dan Liquid cristal Display (LCD). Rangkaian RTC (Real Time Clock) berfungsi sebagai display tanggal dan jamUntuk memudahkan dalam perancangan dan pembuatan, sehingga memperkecil kesalahan.

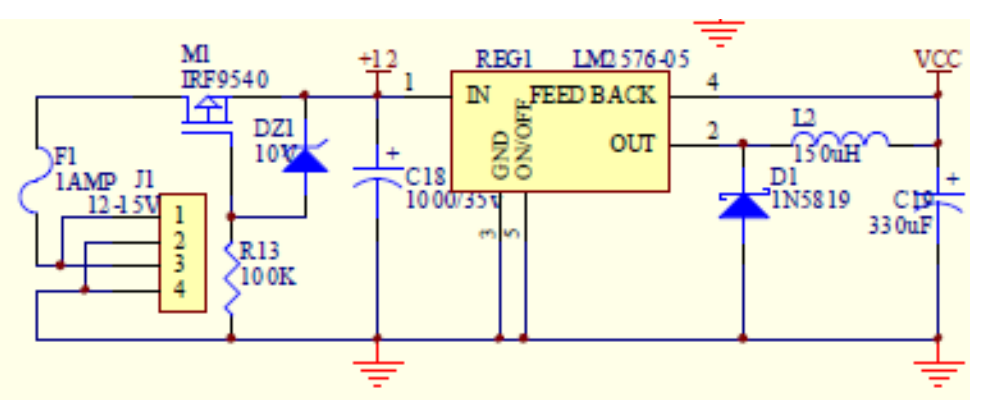

GAMBAR 3. Rangkaian Power Supply sederhana.

Cara pengoperasian alat atau standart prosedur menjalankan alat yakni mengaktifkan alat dengan menghubungkan dengan kontak PLN. Mengoneksikan alat dengan mikrokontoller dan LCD dan berbagai alat elektrik yang lain. Air akan melewati flowsensor kemudian hasil counteran akan ditampilkan di LCD dan mengirim pesan ke pelanggan via sms (short message service).Dari hasil counteran data akan masuk ke database server yang berfungsi sebagai pemyimpan data penghitung pemakaian air. Pelanggan dapat mengetahui tarif air dengan sms ke server sesuai kode masing - masing pelanggan, server akan membalas sms pelanggan dengan tarif harga sesuai penggunaan air per minggu.

Catu daya (power supply) merupakan sumber tenaga yang dibutuhkan suatu rangkaian elektronika untuk bekerja. Besar power supply ini tergantung oleh spesifikasi dari alat masing masing. Pada perancangan sistem pengukuran meteran air digital ini power supply digunakan untuk mensupply rangkaian minimum system, rangkaian sensor.Pada rangkaian power supply pada umumnya kita sering menggunakan IC regulator dalam mengontrol tegangan yang kita inginkan. Regulator tegangan menjadi sangat penting gunanya apabila kita mengaplikasikan 
system power tersebut untuk rangkaian - rangkaian yang membutuhkan tegangan yang sangat stabil.

Real Time Clock merupakan suatu chip (IC) yang memiliki fungsi sebagai penunjuk waktu. RTC DS 12C887 memiliki register yang dapat menunjukkan detik, menit, jam,tanggal, bulan dan tahun. RTC ini di desain memiliki 128 lokasi RAM yang terdiri dari 15 byte untuk data waktu serta kontrol, dan 113 byte sebagai RAM yang dapat digunakan sebagai RAM pada umumnya. RTC DS 12C887 menggunakan bus yang termultipleks untuk menghemat pin. Timing yang digunakan untuk mengakses RTC dapat menggunakan intel timing atau Motorola timing. RTC ini juga dilengkapi dengan pin IRQ untuk kemudahan dalam proses.

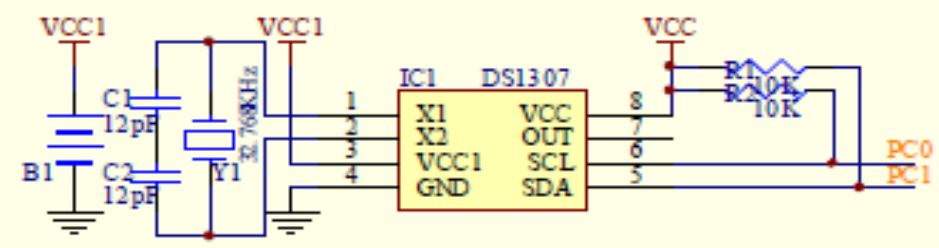

GAMBAR 4. Rangkaian RTC (Real Time Clock).

Mikrokontroler ATMEGA 8535 mempunyai 4 port parallel yakni port A, B, C, dan D, keempat port tersebut bisa dipakai sebagai port parallel dengan 8 bit saluran data, atau digunakan sebagai bit adresseble (satu pin saluran dipakai sebagai pin masukan tersendiri yang terpisah dengan pin-pin yang lain). Pada sistem ini, mikrokontroler mendapatkan input (masukan) dari rangkaian sensor flowmeter $y f-21$ sebagai menghitung debit air dan minimum sytem serial RS 232. Port pada mikrokontroler yang digunakan sebagai port input adalah port 1, port 2 dan port 3 , sedangkan yang berfungsi sebagai port output (keluaran) untuk kabel LCD adalah port C sedangkan kabel data serial port D sebagai RX dan port D sebagai TX. Disamping port masukan dan keluaran, perlu dipasang input reset untuk sistemmikrokontroler pada kaki nomor 9 dengan menambahkan rangkaian komponen resistor sebesar 1 Kilo ohm dan kapasitor elektrolit sebesar $10 \mu \mathrm{F}$.

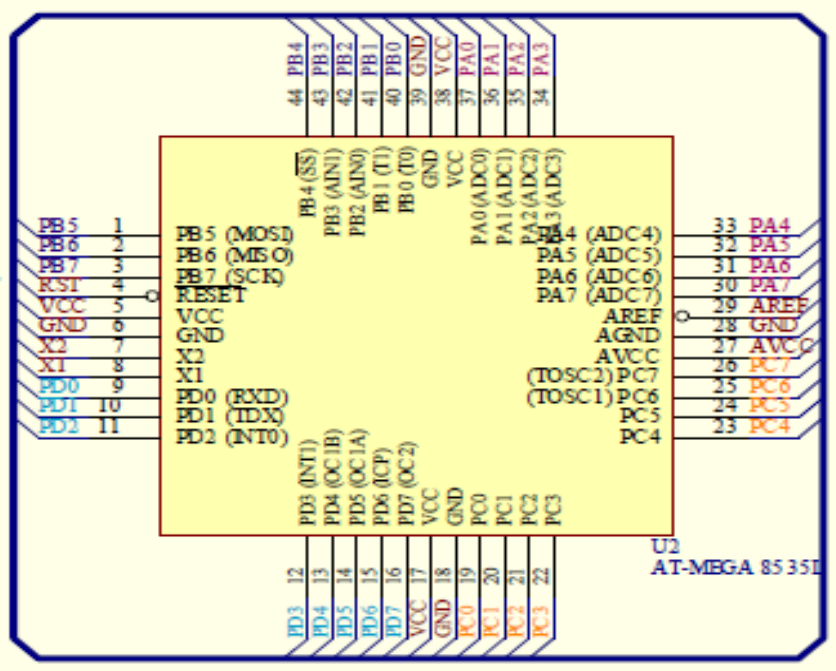

GAMBAR 5. Rangkaian Mikrokontroller ATmega853i.

Sistem mikrokontroler Atmega 8535 ini membutuhkan sumber frekuensi yang didapat dari sebuah rangkaian penguat osilator pembalik (inverting oscillator amplifier) yang tersusun dari sebuah Cristal dengan frekuensi $11.000 \mathrm{MHz}$ dan tiga buah kapasitor keramik sebesar 30pF, 10 pF, dan 0,1 mF yang dihubungkan pada kaki-kaki XTAL1 dan XTAL2 (kaki nomor 18 dan 19).

Sensor aliran adalah alat untuk merasakan laju aliran fluida. Biasanya sensor aliran adalah elemen penginderaan yang digunakan dalam flow meter, atau aliran logger, untuk merekam 
aliran cairan. Seperti yang terjadi untuk semua sensor, akurasi mutlak pengukuran memerlukan fungsi untuk kalibrasi.Ada berbagai macam sensor aliran dan aliran meter, termasuk beberapa yang memiliki baling-baling yang didorong oleh cairan, dan dapat mendorong potensiometer putar, atau perangkat sejenis. Sensor aliran lain didasarkan pada sensor yang mengukur transfer panas yang disebabkan oleh media bergerak.

Prinsip ini umum untuk mikrosensor untuk mengukur aliran.Arus meter berhubungan dengan perangkat yang disebut velocimeters yang mengukur kecepatan cairan yang mengalir melalui mereka. Berbasis laser interferometri sering digunakan untuk pengukuran aliran udara, tetapi untuk cairan, sering kali lebih mudah untuk mengukur aliran. Pendekatan lain adalah metode berbasis Doppler untuk pengukuran aliran. Hall sensor efek juga dapat digunakan, pada katup flapper, atau baling-baling, untuk merasakan posisi baling-baling, seperti pengungsi akibat aliran fluida.
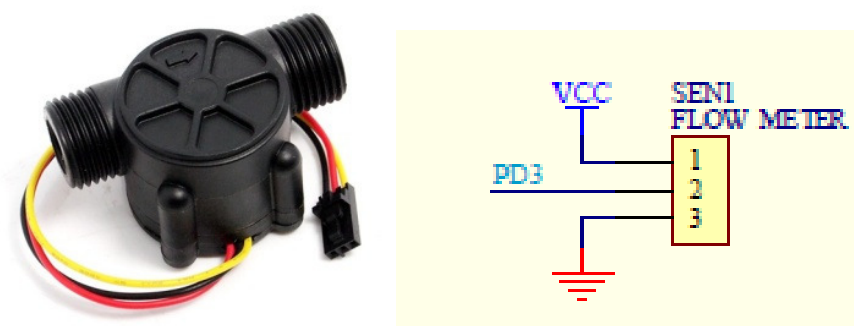

GAMBAR 6. Sensor Flowmeter.

Penelitian ini menggunakan MODEM GSM sebagai media pengiriman sms. Dengan mengkoneksikan MODEM GSM ini dengan hyper terminal kita bias mengatur setting serial port sesuai dengan hardware yang akan kita gunakan. Seperti seting baud rate, stop bit, parity, data bit, dan flow control. Berikut ini adalah gambar dari Modem GSM Wavecom tipe M1360B.

Untuk melakukan komunikasi dengan modem GSM serial, kita menggunakan AT+Command. AT + Command adalah kumpulan perintah yang diawali dengan AT untuk berkomunikasi dengan modem. Berikut ini adalah beberapa perintah-perintah contoh AT + Command yang bias digunakan untuk menggunakan MODEM GSM tipe M1360B :

- AT : M1360B akan membalas "OK" ketika modem telah tersambung dengan PC.

- AT+CMGI : M1360B akan membalas "WAVECOM MODEM" ketika koneksi kabel serial terhubung.

- AT+CSQ : untuk memverifikasi kuat sinyal yang diterima modem.

- ATD $<$ nomerhp $>$ : untuk memeriksa panggilan suara.

- ATH : untuk menghentikan panggilan.

\section{HASIL DAN PEMBAHASAN}

Setelah dilakukan perancangan dan pengukuran air secara digital, maka perlu dilakukan pengujian terhadap alat yang sudah dibuat serta melakukan analisa secara menyeluruh terhadap hasil pengujian tersebut. Hal ini dilakukan dengan tujuan untuk mengetahui performansi alat secara keseluruhan. Pengujian alat secara keseluruhan dilakukan pada perangkat keras (hardware). Rangakaian sensor ini menggunakan sensor flowmeter yf-21sensor ini terdiri dari tubuh plastik katub, rotor air (impeller), dan sensor hall efek. Sensor ini bekerja ketika air mengalir melewati rotor (impeller) akan terjadi perubahan kecepatan dengan tingkatan yang berbeda aliran dan menghasilkan sinyal pulsa dan sinyal tersebut akan mengirim ke mikrokontroller untuk di ubah menjadi debit air agar di konversi menjadi biaya.

Langkah- langkah pengambilan data pengukuran sensor flowmeter :

- Pastikan wiring sudah terkoneksi semua.

- Mengaktifkan stop kontak ke pln.

- Pembacaan sensor flowmeter dengan tampilan digital pada posisi standby. 
- Nyalakan pompa aquarium dan buka valve supaya air bisa mengalir pada pipa dan melewati flowmeter kemudian menuju ke storage B.

- Impeller pada flowmeter akan berputar dan menghasilkan medan magnet sinyal output sensor akan mengirimkan data ke mikrokontroller untuk diolah menjadi frekuensi dan debit air di display (LCD) untuk tampilan frekuensinya dan tampilan debit air.

- Dari hasil pengukuran tersebut konsumen dapat mengetahui jumlah pemakaian debit air dengan mengirim sms ke server.

TABEL 1. Data hasil pengukuran pertama sensor flowmeter YF-21.

\begin{tabular}{|c|c|c|c|c|c|}
\hline No & $\begin{array}{c}\text { Frekuensi } \\
(\mathbf{H z})\end{array}$ & $\begin{array}{c}\text { Flow } \\
(\mathbf{L} / \mathbf{H})\end{array}$ & (x- x rata - rata) & $(\mathbf{x}-\mathbf{x}$ rata)^2 & $\begin{array}{c}\text { Standard } \\
\text { deviasi }(\boldsymbol{\delta})\end{array}$ \\
\hline 1 & 24 & 178 & -7.2 & 51.84 & 2.4 \\
\hline 2 & 25 & 186 & 0.8 & 0.64 & 0.2 \\
\hline 3 & 24 & 178 & -7.2 & 51.84 & 2.4 \\
\hline 4 & 25 & 186 & 0.8 & 0.64 & 0.2 \\
\hline 5 & 26 & 194 & 8.8 & 77.44 & 2.9 \\
\hline 6 & 26 & 194 & 8.8 & 77.44 & 2.9 \\
\hline 7 & 26 & 194 & 8.8 & 77.44 & 2.9 \\
\hline 8 & 24 & 178 & -7.2 & 51.84 & 2.4 \\
\hline 9 & 25 & 186 & 0.8 & 0.64 & 0.2 \\
\hline 10 & 24 & 178 & -7.2 & 51.84 & 2.4 \\
\hline \multicolumn{2}{|c|}{ Rata - Rata } & 185.2 & & 441.6 & \\
\hline
\end{tabular}

Standart Deviasi $=\left[((\mathrm{x}-\mathrm{x} \text { rata }- \text { rata })]^{1 / 2}(\mathrm{n}-1)\right.$

$=7 \mathrm{~L} / \mathrm{H}$

Ralat Mutlak $(\Delta)=\left[\Sigma(\underline{\mathrm{x}-\mathrm{x} \text { rata }- \text { rata })}]^{1 / 2} \mathrm{n}(\mathrm{n}-1)\right.$

$$
=2.21
$$

$$
\sqrt{n} \underset{\sqrt{10}}{\mathrm{U}_{\mathrm{A} 1}}=\quad \underline{\delta}=\underline{7}=2.2
$$

Setelah mendapatkan nilai ralat mutlak yaitu $2.211 / \mathrm{h}$ yang berarti perbaikan untuk nilai flow hanya $2.21 \mathrm{l} / \mathrm{h}$. Kemudian akan dilanjutkan pada penentuan ralat nisbi dibawah ini,

$$
\begin{aligned}
& \text { Ralat nisbi }=\mathrm{I}=\langle\Delta / \text { xrata }- \text { rata }\rangle \times 100 \% \\
& =\langle 2.21 / 185.2\rangle \times 100 \% \\
& =1.1 \%
\end{aligned}
$$

Untuk mendapatkan nilai keseksamaan maka sebelumnya diperoleh hasil ralat nisbi sebesar 1.1 $\%$. Keseksamaan (Accuracy) $=\mathrm{K}=100 \% \quad-\mathrm{I}=100 \%-1.1 \%=98.9 \%$. Dari pengambilan data pengujian maka di ambil 5 data untuk dilakukan perhitungan dan perbandingan data actual dengan data sensivity untuk menemukan nilai error dari sensor.

Pengujian Flowmeter dengan tampilan digital dengan dialiri air dengan pembacaan frekuensi 24 Hz. Langkah pengujian :

- Pembacaan sensor flowmeter dengan tampilan digital pada posisi standby.

- Nyalakan pompa aquarium dan buka valve supaya air bisa mengalir pada pipa dan melewati flowmeter.

- Impeller pada flowmeter akan berputar ketika air melewati sensor dan angka pada display (LCD) untuk tampilan frekuensinya menunjukkan $24 \mathrm{~Hz}$ dan pada tampilan 
debit menunjukkan angka 178 liter/h. Hasil ini akan di bandingkan dengan menggunakan rumus.

Diketahui :
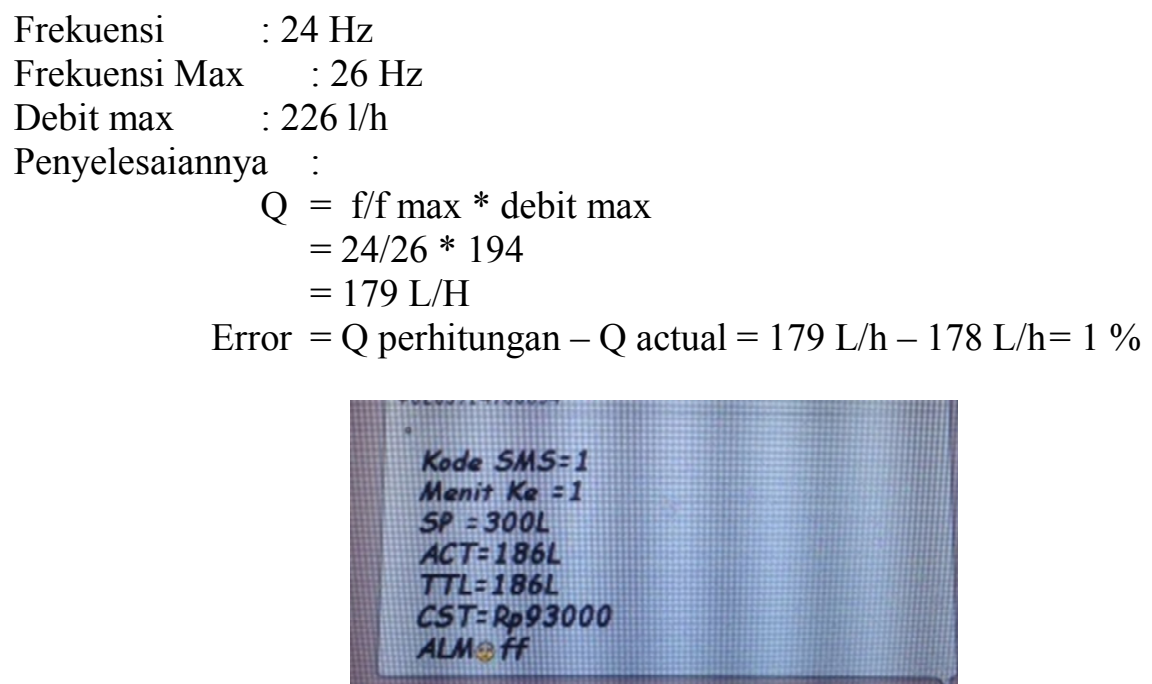

GAMBAR 7. Bukti pengiriman debit $186 \mathrm{~L} /$ hourdengan $25 \mathrm{~Hz}$.

Dari hasil perhitungan yang telah di lakukan pada tabel 2 kemudian di buatkan grafik perbandingan antara data perhitungan dan data pengujian.

TABEL 2. Data hasil pengukuran pertama sensor flowmeter YF-21 untuk perhitungan.

\begin{tabular}{|c|c|c|c|}
\hline No & $\begin{array}{c}\text { Frekuensi } \\
(\mathbf{H z})\end{array}$ & $\begin{array}{c}\text { Flow } \\
(\mathbf{L} / \mathbf{H})\end{array}$ & $\begin{array}{c}\text { Eror = Data } \\
\text { Perhitungan - Data } \\
\text { aktual }\end{array}$ \\
\hline 1 & 24 & 178 & 1 \\
\hline 2 & 24 & 178 & 1 \\
\hline 3 & 25 & 186 & 0.5 \\
\hline 4 & 25 & 186 & 0.5 \\
\hline 5 & 26 & 194 & 0 \\
\hline
\end{tabular}

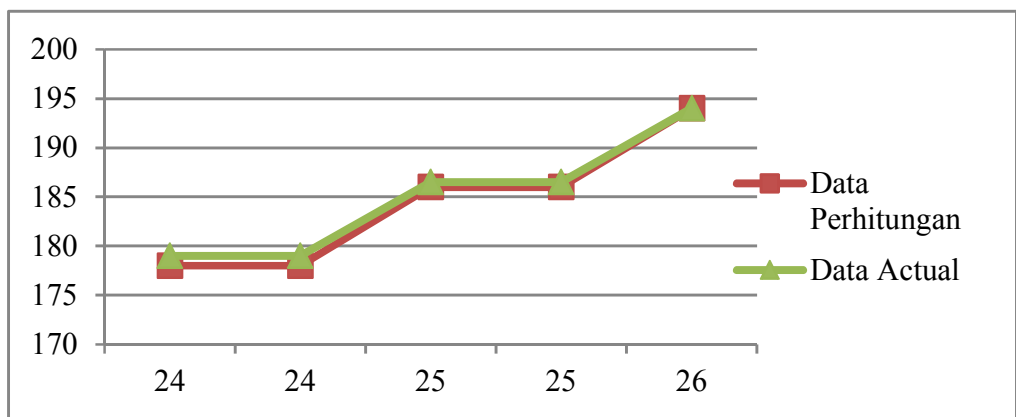

GAMBAR 8. Grafik perbandingan data perhitungan dan data aktual pertama.

\section{KESIMPULAN}

Sensor flow yf-21 adalah sensor yang digunakan untuk mengukur flow (aliran) dengan menggunakan impeller sebagai media perantaranya. Prinsip kerja dari sensor flow yf-21 adalah ketika impeller berputar akan mengubah energi gerak ke resistansi untuk menghasilkan sinyal pulsa agar dapat di baca oleh mikrokontroller. Debit pemakaian yang dikeluarkan oleh alat dapat di monitoring dengan menggunakan media handphonedan mikrokontroller, dimana 
jumlahnya tergantung pada jumlah counter-an yang telah di konversi ke dalam rupiah. Alat ukur flow ini memiliki nilai keseksamaan (Accuracy) 98.9 \%. Semakin tinggi nilai flowrate maka nilai error akan semakin kecil dan semakin kecil nilai flowrate yang terjadi maka nilai error maka akan semakin besar.

\section{DAFTAR PUSTAKA}

[1] Slamet Riyadi dan Bambang Eka Purnama, Indonesian Journal on Networking and Security 2, 2013.

[2] Paulus Andi Nalwan, Panduan Praktis Teknik Antarmuka dan Pemrograman Mikrokontroller ATMEGA 8535. Jakarta: PT. Elex Media Komputindo, 2003.

[3] Rohman F., "Prototype Alat Pengukur Kecepatan Aliran Air Dan Debit Air (Flowmeter) Dengan Tampilan Digital", Skripsi, Universitas Gunadarma, 2009.

[4] Ary Pudiatmoko, "Sistem Keamanan Kamar Kos Dengan Peringatan Alarm Dan SMS Berbasis Mikrokontroler ATMEGA32", Skripsi, Universitas Muhammadiyah Surakarta, 2013.

[5] Ferry Andika P, Irkhos dan Rida Samdara, Jurnal Gradien 8, 2012, pp. 780-783.

[6] Fanny Astria, Mery Subito dan Deny Wiria Nugraha, Jurnal Mektrik 1, 2014, pp. 47-55.

[7] Yopi Marjuki, Sri Ratna Sulistiyanti dan F. X. Arinto Setiawan, ELECTRICIAN Jurnal Rekayasa dan Teknologi Elektro 2, 2008, pp. 191-198.

[8] Made Bayu Pranata, I Gusti Agung Putu Raka Agung dan Pratolo Rahardjo, Jurnal Ilmiah SPEKTRUM 2, 2015, pp. 58-64. 